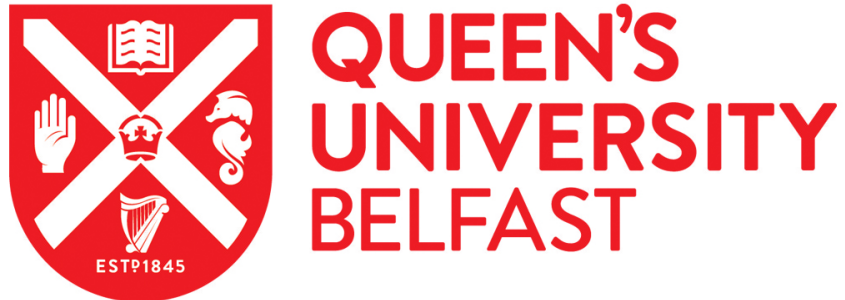

\section{Can a carbon nano-coating resist metallic phase transformation in silicon substrate during nanoimpact?}

Goel, S., Agrawal, A., \& Faisal, N. H. (2014). Can a carbon nano-coating resist metallic phase transformation in silicon substrate during nanoimpact? Wear, 315(1-2), 38-41. https://doi.org/10.1016/j.wear.2014.03.009

\section{Published in:}

Wear

\section{Document Version:}

Peer reviewed version

Queen's University Belfast - Research Portal:

Link to publication record in Queen's University Belfast Research Portal

\section{Publisher rights}

NOTICE: this is the author's version of a work that was accepted for publication in Wear. Changes resulting from the publishing process, such as peer review, editing, corrections, structural formatting, and other quality control mechanisms may not be reflected in this document. Changes may have been made to this work since it was submitted for publication.

\section{General rights}

Copyright for the publications made accessible via the Queen's University Belfast Research Portal is retained by the author(s) and / or other copyright owners and it is a condition of accessing these publications that users recognise and abide by the legal requirements associated with these rights.

Take down policy

The Research Portal is Queen's institutional repository that provides access to Queen's research output. Every effort has been made to ensure that content in the Research Portal does not infringe any person's rights, or applicable UK laws. If you discover content in the Research Portal that you believe breaches copyright or violates any law, please contact openaccess@qub.ac.uk. 


\title{
Can a carbon nano-coating resist metallic phase transformation in silicon substrate during nanoimpact?
}

\author{
Saurav Goel ${ }^{\mathrm{a}^{*}}$, Anupam Agrawal $^{\mathrm{b}}$ and Nadimul Haque Faisal \\ ${ }^{a}$ School of Mechanical and Aerospace Engineering, Queen's University, Belfast, BT95AH, UK \\ ${ }^{b}$ Department of Business Administration, University of Illinois at Urbana-Champaign, USA \\ ${ }^{\mathrm{c}}$ School of Engineering, Robert Gordon University, Garthdee Road, Aberdeen, AB107GJ, UK
}

*Corresponding author Tel.: +44-028-90975625, Email address: s.goel@qub.ac.uk, Fax: +44-028-90974148

\begin{abstract}
Nanomechanical response of a silicon specimen coated with a $s p^{3}$ crystalline carbon coating (1.8 nm thickness) was investigated using MD simulation. A sharp conical rigid tip was impacted at the speed of $50 \mathrm{~m} / \mathrm{sec}$ up to a depth of $\sim 80 \%$ of the coating thickness. Unlike pure silicon specimen, no metallic phase transformation was observed i.e. a thin coating was able to resist $\mathrm{Si}$-I to $\mathrm{Si}$-II metallic phase transformation signifying that the coating could alter the stress distribution and thereby the contact tribology of the substrate. The stress state of the system, radial distribution function and the load-displacement curve were all aligned with above observations ${ }^{1}$.
\end{abstract}

\section{Keywords: MD simulation; phase transformation; silicon; carbon; coating; nanoimpact}

\section{Introduction}

High pressure phase transformation (HPPT), now known as the Herzfeld-Mott transition [1] causes metallization of brittle materials (group-IV elements) [2]. HPPT thus induces metal like behaviour because of the closure of the valence-conduction band gap due to overlap of wave functions and hence delocalization of the valence electrons [3]. An example of such a case is silicon, where during its contact loading (such as during nanoindentation, nanometric cutting and nanoimpact), a hydrostatic pressure of about 11-16 GPa [4] results in the transformation of the Si-I (cubic diamond structure) into a more dense metallic Si-II phase having a $\beta$-tin structure [5] of silicon. Recently, thin films are being frequently used as protective coatings - for instance, on magnetic and optical storage disks, optical windows, biomedical and micro/nano-electromechanical (MEMS/NEMS) devices [6]. Consequently, there is a growing interest on advancing the understanding on the nanomechanical behaviour of the films and the substrate. The objective of this work is inspired from recent experimental works [7-8] on thin films and is focused on supplementing those investigations by carrying out a theoretical investigation concerning the occurrence of high pressure phase transformation during nanoimpact in a silicon substrate which is coated by a pure crystalline $s p^{3}$ bonded carbon film. Phase transformation of brittle materials is of particular interest to the field of nanometric cutting because it provides the roadmap to obtain the ductile response from brittle materials [9]. An understanding of how high pressure phase transformation can be regulated is necessary to know to control the deviatoric stress conditions in order to drive or suppress ductile response of brittle materials such as during machining of silicon [9-10].

\section{MD Model}

In this work, molecular dynamics (MD) simulation is applied to study the nanomechanical response of a silicon specimen coated with a crystalline thin film of $s p^{3}$ carbon. The objective of this study was to

\footnotetext{
${ }^{1}$ Readers are requested to refer to the web based version for correct interpretation of the colour legends.
} 
study a pure system to see the maximum theoretical limits of Young's modulus (E), therefore a pure $s p^{3}$ carbon film (and not an amorphous thin film) was chosen. The simulation was performed using LAMMPS [11] assuming the indenter tip to be a rigid body. Analytical bond order potential (ABOP) and reactive empirical bond order (REBO) potential functions were used to describe the covalent descriptions of silicon and carbon respectively [12]. The algorithm followed in this work is the same as has been used in the previous investigations [6, 13-14]. Additionally, an automated Dislocation Extraction Algorithm (DXA) [15-18] was also used to visualize and analyze the atomistic simulation data to identify dislocation lines. Additional trials were performed by varying the shape of the indenter (spherical and pyramidal) and depth of the indentation (performing indentation at depths less than $80 \%$ of the coating thickness) but the coating still resisted the Si-I to Si-II phase transformation in the substrate. For brevity, only one case is presented here where the thickness of the coating was about 1.8 $\mathrm{nm}$, and the height and the diameter of the indenter were chosen as $1.8 \mathrm{~nm}$ and $2.7 \mathrm{~nm}$ respectively while the depth of impact was $1.5 \mathrm{~nm}$ at the speed of $50 \mathrm{~m} / \mathrm{sec}$. An MD simulation without involving any coating was also performed as a precursor to the main trial, and in the system without coating, the measure of coordination number and radial distribution function showed clear evidence of phase transformation of silicon (The results obtained from the simulation without coating are not reported for brevity) as is well known from the experiments and simulations [19].

\section{Results and discussions}

Figure 1 show the force-displacement $(P-h)$ plot obtained from the MD simulation. The force variation shown in figure 1 relates to the deformation, cohesion and recovery of atoms. The plot has been divided into various stages shown in figure 1. Landman et al. [20-21] have highlighted that even when the atoms of the tip and the substrate are strained, they try to optimize their embedding energies while maintaining their individual material cohesive binding energies. This leads to a jump out contact in the $P$ - $h$ plot represented as point B. As the indenter continues to move, a monotonic increase of forces can be seen until point $\mathrm{C}$. At point $\mathrm{C}$, few carbon-carbon bonds were observed to fracture in order to accommodate the indenter inside the coating. Due to the fracture of the thin coating at this point, the forces on the indenter decrease suddenly. However, after this point other $\mathrm{C}-\mathrm{C}$ bonds were observed to stretch further which causes an increase in the forces on the indenter. This increase once again exhibited monotonic nature until point $\mathrm{D}$ where the forces were found to decrease. Simulation video showed that this sudden drop at point $\mathrm{D}$ was on account of the disturbances in the crystal lattice structure in the substrate. These were the major stages captured from the simulation during the loading stage of the indenter. 


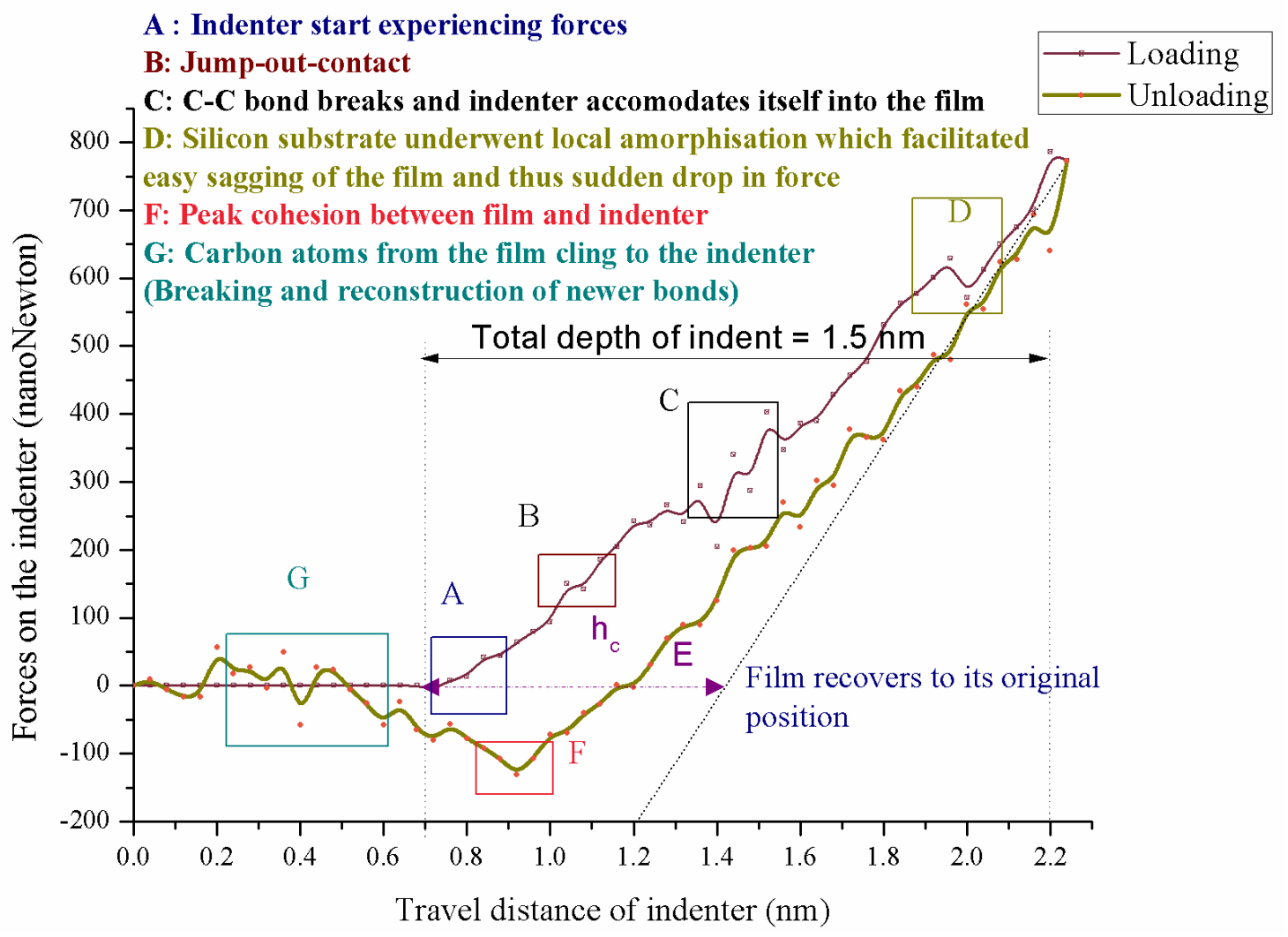

Figure 1: Force-displacement $(P-h)$ curve obtained from the MD simulation

During unloading, the indenter retracts and consequently the force on the indenter decreases. During this stage, the carbon coating restores its original position until point E. Thereafter, cohesion between the carbon atoms of the coating and indenter tip becomes more pronounced. Consequently, cohesive forces attract the indenter towards the coating while the physical velocity of the indenter is in a direction opposite to that of the cohesive force. Relatively large retraction force of the indenter causes negative display of forces and a pronounced force hysteresis between point $E$ and point $F$. At point $F$, as the indenter continues to retract, the cohesive bond length between the carbon atoms of the coating and the indenter stretches to its maximum limit. Beyond this point, the ultimate separation occurs when the inter-atomic distance between the last two bonded C-C atoms exceeds $1.75 \AA$. Zavitsas et al. [22] assert that $1.75 \AA$ is the maximum possible bond length between two carbon atoms, which is consistent with the current simulation results. The force hysteresis therefore was found related to and originating from the cohesive dynamics between the carbon atoms of the coating and the diamond tip. Depending on the depth of the impact, energy transferred from the indenter to the coating and the stresses induced during the process may result in a backward (negative) depth deviation [6]. Further work in this direction can be referred elsewhere [6,23].

Although a quantitative measure of separation distance of $\mathrm{C}-\mathrm{C}$ bond provides confidence in the MD simulation, the authors also conducted an evaluation of the modulus of elasticity from the loading and unloading curve shown in figure 1. This was accomplished by applying the Oliver and Pharr method [24], which enables an estimation of the contact area directly from the P-h curve without assessment of the actual contact area of the indenter. An imaginary line on the unloading curve was plotted by following the power law along the unloading curve on the top $1 / 3^{\text {rd }}$ part. The elastic modulus of the coating was obtained as $405 \mathrm{GPa}$ (considering $h_{c}=0.924 \mathrm{~nm}$ at $P_{\max }=750 \mathrm{nN}$ and slope $=937.5$ $\mathrm{N} / \mathrm{m}$ ). This theoretical value may be difficult to realize experimentally owing primarily to the differences such as sample roughness, air lubrication, sensitivity of the equipment, purity of the material, and accuracy of measurement which may influence the experimental results. However, by extrapolation in the modulus value to the zero depth as is done in ISO14577 seems to reveal the same 
value of $E$ for a pure $s p^{3}$ coating.
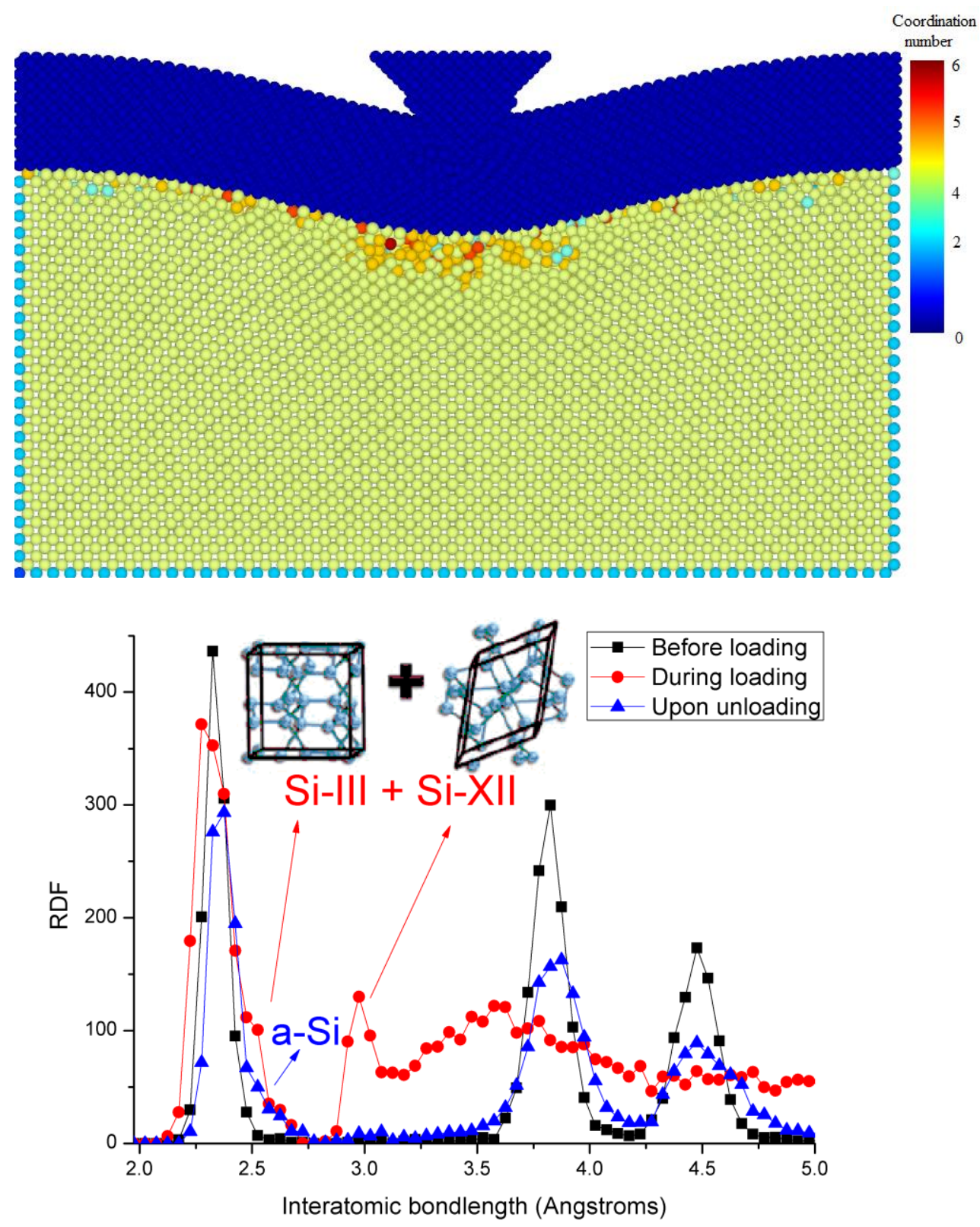

Figure 2: Changes in the crystal structure of silicon (a) variation in the coordination number of the silicon substrate. The coordination number of carbon was not calculated and therefore shown as zero (b) Local radial distribution function (RDF) of the silicon atoms in the substrate.

During loading stage, the material below the indenter compresses and consequently sagging of the coating becomes ostensibly visible. This brings a lot of lattice disorder in the carbon coating and also in the silicon substrate. Change in coordination number (which is a well identified measure to monitor phase transformation in crystalline materials [25]) and radial distribution functions were used to observe such changes and one such result is shown in figure $2 \mathrm{a}$. It can be seen from figure $2 \mathrm{a}$ that the bulk of single crystal silicon has a coordination number of 4 which is indicative of a covalently bonded crystalline system in its stable diamond cubic lattice structure. Atoms with zero coordination value are the ones which were not included in the computation. In the deformation zone, a large number of atoms showed a coordination value of five. These data suggest that unlike classical contact loading of silicon, 
metallic phase transformation leading to formation of $\beta$-silicon (6 coordination number) did not occur. This finding seems to be in line with several experimental observations [26-28], where no metallic phase of silicon ( $\beta$-silicon) was found when a thin film on a substrate was indented. Since experimental and simulation results corroborate each other, the simulation size scale chosen in the current work seems insensitive to the MD simulation results.

To explore this even further, radial distribution function (RDF) of silicon was plotted at three stages i.e. before loading, during peak loading and after unloading (figure $2 b$ ). It can be seen that silicon exhibited additional peaks at around $2.5 \AA$ and $3.0 \AA$ during peak loading. These peaks (separately highlighted in red and blue colours) were different from the crystalline peaks (black colour). The state of the stress in the silicon substrate and the coordination number measurement in accordance with the radial distribution function support the assertion that the pristine silicon substrate underwent $\mathrm{Si}$-III and Si-XII metastable phases and reverted to the amorphous mixture of silicon upon release of the indentation load rather than undergoing metallic phase transformation (Si-II).

This finding is in contrast to the case of a classical nanoindentation test where the metallic phase of $\beta$-silicon can immediately be observed upon indentation of a silicon substrate. While the existence of metastable phases can bring the structural changes in the crystal lattice described above, these may not be the only cause of the reduced elastic modulus of the carbon coating. It was based on these observations that conclusion was made by Haq et al. [28] that unlike classical nanoimpact, thin film acts as a barrier to promote sufficient magnitude of pressure at the film-substrate interface to drive the high pressure phase transformation (HPPT) of pristine silicon to metallic $\beta$-silicon. These observations also suggest strongly that non observation of metallic phase and appearance of amorphous silicon in MD simulation complements the experimental findings.

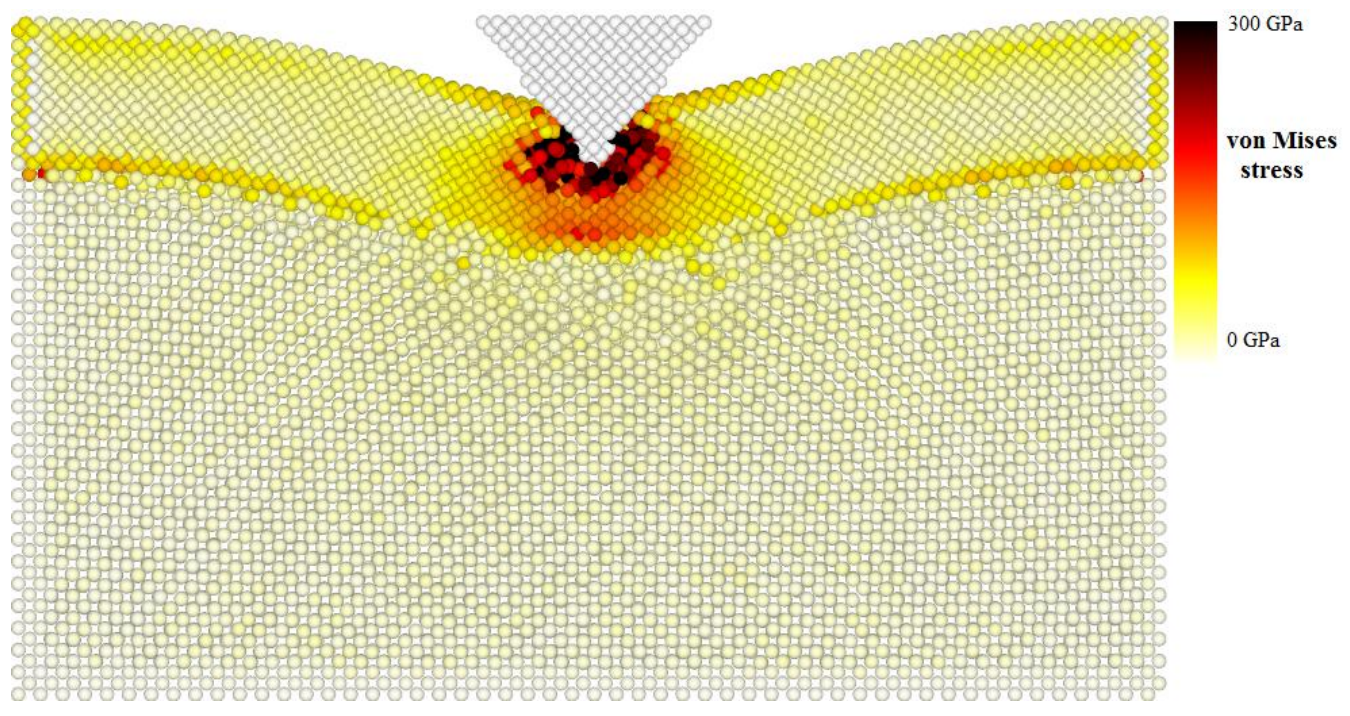



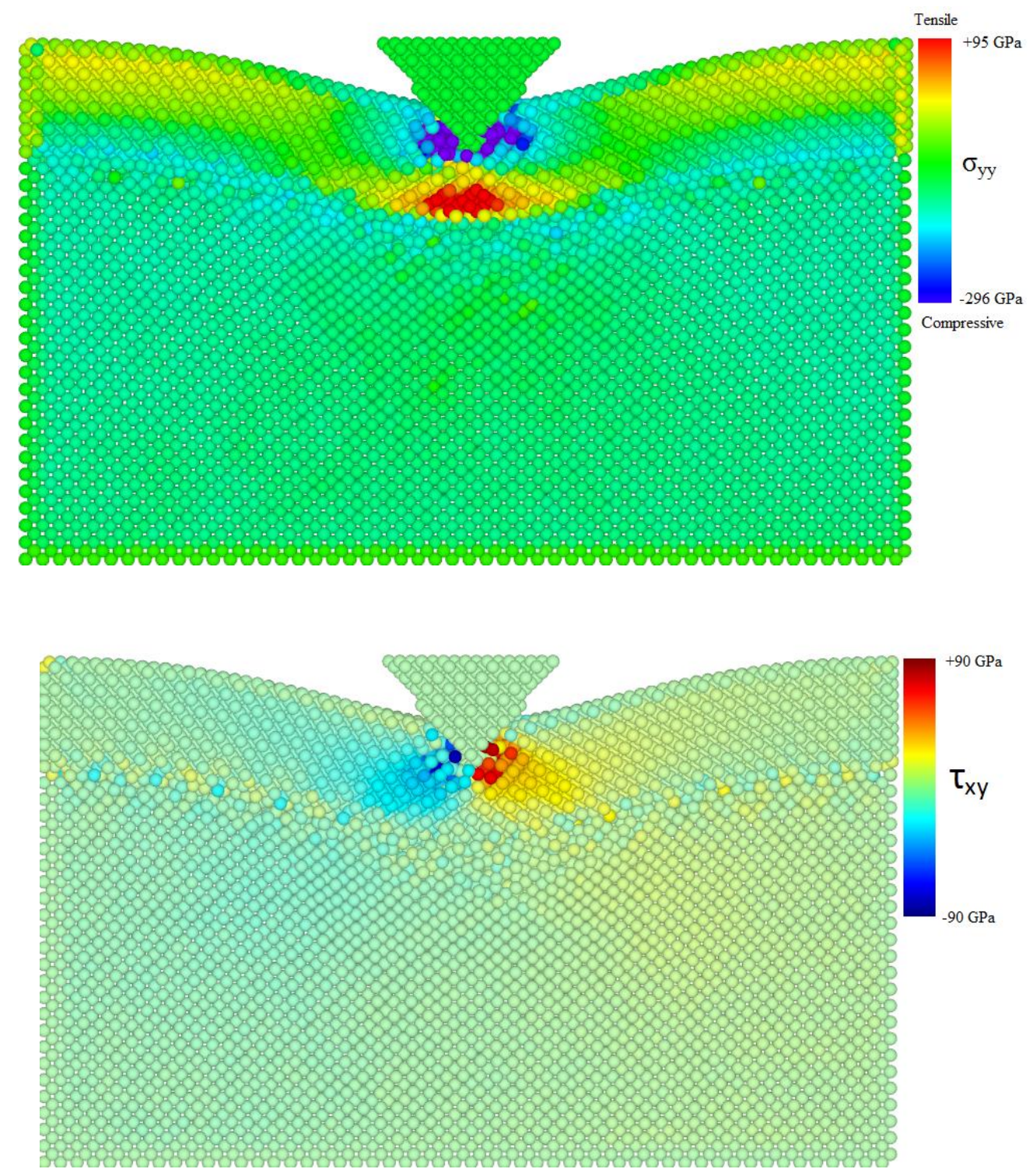

Figure 3: Representation of the atomic stresses: (a) von Mises stresses, (b) compressive stresses, and (c) shear stress.

To gain further insights into this phenomenon, stress states of atoms were obtained from the simulation. Figure 3 shows the von Mises stress, compressive stress and shear stress [29]. It can be seen from figure 3(a) that carbon atoms in the coating underwent local distortion and were subjected to peak von Mises stresses of up to $300 \mathrm{GPa}$ involving the component of shear stress of up to $90 \mathrm{GPa}$. The interesting finding from the plot of compressive stress (figure 3(b)) is that the internal extreme layer of coating undergoes a compressive stress while the external extreme layer (near to the substrate) undergoes tensile stress. The classical theory of simple bending states that stress state remains compressive at any point above the imaginary neutral axis and tensile below the imaginary neutral axis when a beam undergoes a pure sagging moment. In line with this theory, it was observed that the internal extreme layer of coating showed a compressive stress of about -296 GPa while the external extreme layer showed a tensile stress of about $95 \mathrm{GPa}$. At peak loading, the peak von Mises stress in the silicon substrate was computed to be only about $10 \mathrm{GPa}$ which is insufficient to cause metallic phase transformation of silicon as reported in the literature [4]. Gogotsi et al. [2, 30] have suggested that lack of sufficient stresses can activate other phases of silicon such as (Si-III which is a bc8 form of silicon) and Si-XII (which is a rombohedral form). This transformation results in a volumetric reduction of the 
atomic volume of silicon by about $10 \%$ and is in accordance with the observations revealed by RDF in figure $2 b$ shown earlier.

To identify whether HPPT alone was the mechanism underneath the plastic behaviour or any dislocation motion was involved, an automated dislocation algorithm (DXA) [16-17] was used. Two snapshots were obtained from the dislocation analysis (figure 4): First at the peak loading stage and second after the unloading. At these stages during the impact, DXA did not showed any nucleation of dislocation or dislocation lines. It is however possible that a number of other parameters like depth of impact, geometry of the probe, and speed of the impact may result in dislocation nucleation at other impact parameters. This will however not bring any change in the high pressure phases of the substrate.

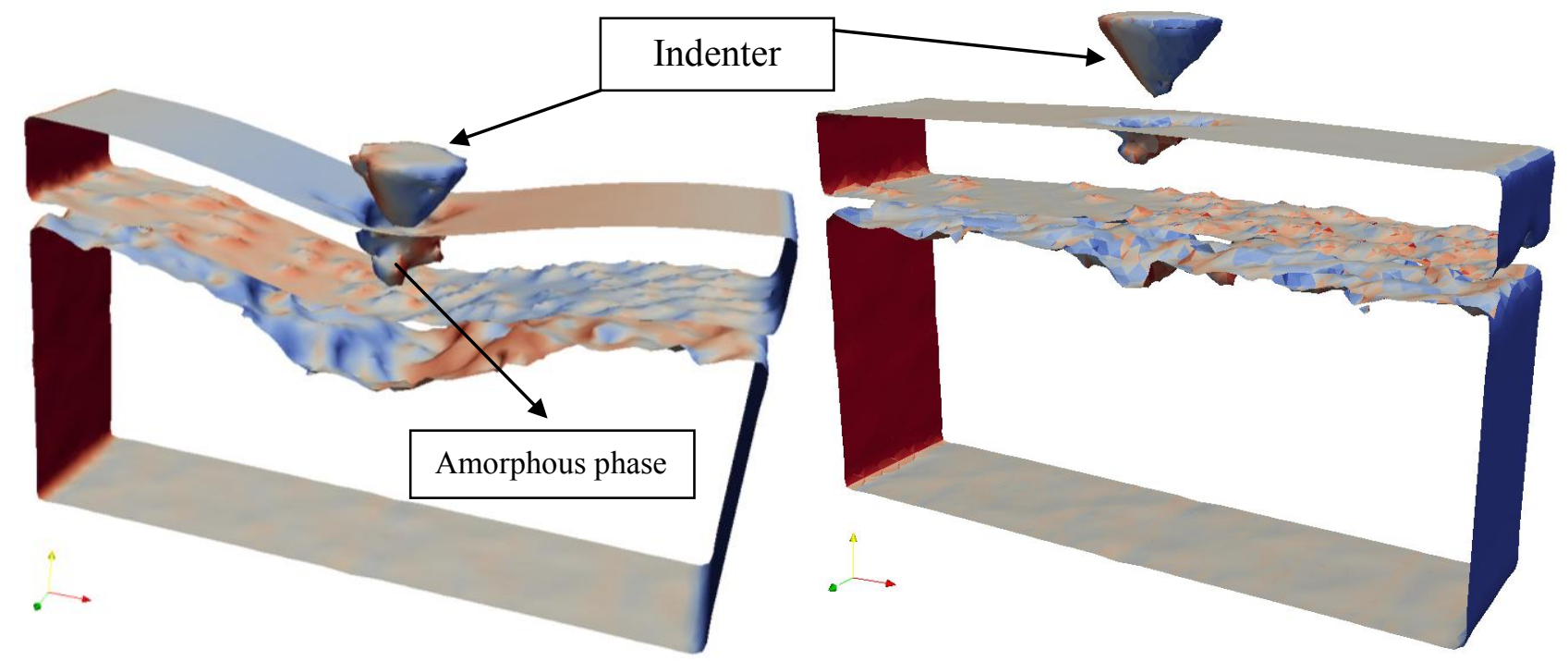

Figure 4: Output of the DXA algorithm (a) at peak loading and (b) unloading showing no dislocations. The geometric boundaries of silicon and coating are shown, while the geometric boundaries of the disordered phase are not visible in these visualizations

\section{Conclusions}

In summary, MD simulation shows that even a thin carbon coating (of several nanometer thickness) can change the contact tribology during nanoimpact. The physical existence of coating alters the deviatoric stress distributions on the silicon during the nanoimpact. The distribution of stresses over the entire surface area prevents concentration of the required magnitude of stresses right underneath the indenter. Consequently, no metallic phase transformation of silicon was observed and instead other phases of silicon such as Si-III and Si-XII were observed. Crucially, the changed contact tribology resulted in evenly distributed contact stresses and eventually resisted the metallic phase transformation in silicon during its nanoimpact, which is at variance with the results observed during nanoimpact of bulk silicon. This finding can stimulate future work on contact tribology of thin coatings.

\section{References:}

[1] J.J. Gilman, Insulator-metal transitions at microindentations, J Mater Res, 7 (1992) 535-538.

[2] V. Domnich, Y. Gogotsi, Phase transformations in silicon under contact loading, Rev Adv Mater Sci, 3 (2001).

[3] S. Goel, X. Luo, R.L. Reuben, Shear instability of nanocrystalline silicon carbide during nanometric cutting, Appl Phys Lett, 100 (2012) 231902.

[4] S.K. Deb, M. Wilding, M. Somayazulu, P.F. McMillan, Pressure-induced amorphization and an amorphous-amorphous transition in densified porous silicon, Nature, 414 (2001) 528-530. 
[5] S. Goel, X. Luo, R.L. Reuben, W.B. Rashid, Replacing diamond cutting tools with CBN for efficient nanometric cutting of silicon, Mater Lett, 68 (2012) 507-509.

[6] N.H. Faisal, R. Ahmed, S. Goel, Y.Q. Fu, Influence of test methodology and probe geometry on nanoscale fatigue failure of diamond-like carbon film, Surface and Coatings Technology, 242 (2014) 42-53.

[7] L. Chen, M.C. Yang, C.F. Song, B.J. Yu, L.M. Qian, Is 2nm DLC coating enough to resist the nanowear of silicon, Wear, 302 (2013) 909-917.

[8] S. Miyake, S. Yamazaki, Nanoscratch properties of extremely thin diamond-like carbon films, Wear, 305 (2013) 69-77.

[9] P.S. Pizani, R. Jasinevicius, J.G. Duduch, A.J.V. Porto, Ductile and brittle modes in single-pointdiamond-turning of silicon probed by Raman scattering, J Mater Sci Lett, 18 (1999) 1185-1187.

[10] R.G. Jasinevicius, J.G. Duduch, L. Montanari, P.S. Pizani, Phase transformation and residual stress probed by Raman spectroscopy in diamond-turned single crystal silicon, Proceedings of the Institution of Mechanical Engineers, Part B: Journal of Engineering Manufacture, 222 (2008) 1065-1073.

[11] S. Plimpton, Fast Parallel Algorithms for Short-Range Molecular Dynamics, J Comput Phys, 117 (1995) 1-19.

[12] S. Goel, A topical review on our current understanding on diamond machining of silicon carbide (in press), Journal of Physics D : Applied Physics, IOP, (2014).

[13] S. Goel, X. Luo, R. Reuben, W.B. Rashid, Atomistic aspects of ductile responses of cubic silicon carbide during nanometric cutting, Nanoscale Research Letters, 6 (2011) 589.

[14] S. Goel, X. Luo, R.L. Reuben, H. Pen, Influence of temperature and crystal orientation on tool wear during single point diamond turning of silicon, Wear, 284-285 (2012) 65-72.

[15] A. Stukowski, Structure identification methods for atomistic simulations of crystalline materials, Model Simul Mater Sc, 20 (2012) 045021.

[16] A. Stukowski, K. Albe, Extracting dislocations and non-dislocation crystal defects from atomistic simulation data, Model Simul Mater Sc, 18 (2010) 085001.

[17] A. Stukowski, V.V. Bulatov, A. Arsenlis, Automated identification and indexing of dislocations in crystal interfaces, Model Simul Mater Sc, 20 (2012) 085007.

[18] S. Goel, A. Stukowski, X. Luo, A. Agrawal, R.L. Reuben, Anisotropy of single-crystal 3C-SiC during nanometric cutting, Model Simul Mater Sc, 21 (2013) 065004.

[19] S. Goel, X. Luo, A. Agrawal, Advances in diamond machining of silicon through molecular dynamics simulation and experiments (Under Review), Int J Mach Tool Manu, (2014).

[20] U. Landman, R.N. Barnett, W.D. Luedtke, Simulations of Materials: From Electrons to Friction, Philosophical Transactions of the Royal Society of London. Series A: Physical and Engineering Sciences, 341 (1992) 337-350.

[21] U. Landman, W.D. Luedtke, N.A. Burnham, R.J. Colton, Atomistic Mechanisms and Dynamics of Adhesion, Nanoindentation, and Fracture, Science, 248 (1990) 454-461.

[22] A.A. Zavitsas, The Relation between Bond Lengths and Dissociation Energies of Carbon-Carbon Bonds, The Journal of Physical Chemistry A, 107 (2003) 897-898.

[23] S. Goel, J. Yan, X. Luo, A. Agrawal, Incipient plasticity in 4H-SiC during quasistatic nanoindentation (http://dx.doi.org/10.1016/j.jmbbm.2013.12.005), Journal of the Mechanical Behavior of Biomedical Materials, (2014).

[24] W.C. Oliver, G.M. Pharr, Improved technique for determining hardness and elastic modulus using load and displacement sensing indentation experiments, J Mater Res, 7 (1992) 1564-1583.

[25] S. Goel, X. Luo, R.L. Reuben, Molecular dynamics simulation model for the quantitative assessment of tool wear during single point diamond turning of cubic silicon carbide, Comp Mater Sci, 51 (2012) 402-408.

[26] B.D. Beake, S.P. Lau, Nanotribological and nanomechanical properties of 5-80 nm tetrahedral amorphous carbon films on silicon, Diam Relat Mater, 14 (2005) 1535-1542.

[27] J. Chen, X. Guo, Q. Tang, C. Zhuang, J. Liu, S. Wu, B.D. Beake, Nanomechanical properties of graphene on poly(ethylene terephthalate) substrate, Carbon, 55 (2013) 144-150. 
[28] A.J. Haq, P.R. Munroe, M. Hoffman, P.J. Martin, A. Bendavid, Nanoindentation-induced deformation behaviour of diamond-like carbon coatings on silicon substrates, Thin Solid Films, 515 (2006) 1000-1004.

[29] S. Goel, W.B. Rashid, X. Luo, A. Agrawal and V.K. Jain, A theoretical assessment of surface defect machining and hot machining of nanocrystalline silicon carbide (in press), DOI:10.1115/1.4026297, J. Manuf. Sci. Eng.. (ASME), (2013).

[30] G. Yury, Z. Guohui, K. Sang-Song, C. Sabri, Raman microspectroscopy analysis of pressureinduced metallization in scratching of silicon, Semicond Sci Tech, 16 (2001) 345. 